\title{
Results from the Implementation of a Surgical Safety Checklist (SSC) at an Interventional Radiology Unit
}

\author{
Christian Schnedl $^{1 *}$, Gerald Sendlhofer ${ }^{2,3}$, Hannes Deutschmann ${ }^{1}$ \\ From Safety in hospitals: from strategy to implementation Annual Scientific Meeting 2015 \\ Graz, Austria. 29-30 September 2015
}

\section{Background}

The awareness of the necessity of a strong safety culture is of utmost importance to enhance patient's safety and has been reiterated for years in the healthcare system $[1,2]$.

Therefore, a surgical safety checklist (SSC) was implemented in a pilot phase to improve and optimize patient's safety during interventional procedures at the division for vascular and interventional radiology in autumn 2014, where on average 4,000 procedures/per year are performed.

The purpose of this retrospective analysis was to analyze SSC-compliance in order to adapt and ameliorate it, respectively.

\section{Material and methods}

The SSC adapted from the WHO SSC to local circumstances consisted of three phases comprising the sign-in (SI) phase (before administration of anesthesia), the team time out (TTO) and sign out (SO) phases (comprising the core interventional procedure).

Figure 1 shows the implemented SSC with its three items, which has to be fully checked and marked before continuing the next procedural step by the responsible expert.

To assess the SSC compliance rate an internal audit was performed for two days (October $14^{\text {th }}$ and $15^{\text {th }}$ 2015 ) in the pilot phase. The SSCs were compared to performed operations by the Department of Quality and Risk Management as the number of collected SSCs was matched with scheduled and definitely performed

\footnotetext{
* Correspondence: christian.schnedl@medunigraz.at

'Division of Vascular and Interventional Radiology, Department of Radiology, Medical University of Graz, Graz, Austria

Full list of author information is available at the end of the article
}

operations. Corresponding data were gained from hospital's electronic documentation system.

The primary endpoint included the use of the SSC generally as well as the respective completion rate in cases the SSC was used.

Data were analyzed descriptively, using absolute and relative frequencies for categorical variables.

\section{Results}

On October $14^{\text {th }} / 15^{\text {th }}, 1$ month after starting the pilot phase, the SSC was used in $42.3 \%(11 / 26)$ of interventional procedures. Within used SSCs, 27.3\% (3/11) were complete, while $72.7 \%(8 / 11)$ were partially complete (Figure 2).

In partially completed SSCs checkbox completion varied significantly, especially the TTO- and SO-items were missing in total in 3 and 4 checklists, respectively. The most common missing single checkbox item was "informed consent" in $27.3 \%$ (3/11) of partially completed checklists.

\section{Conclusions}

As summarized by Treadwell [3], barriers to SSC implementation generally consist of confusion regarding the proper use of the checklist, pragmatic challenges to efficient work flow and individual beliefs and attitudes.

Especially for short and periodical interventional procedures (i.e. change of nephrostomy catheter, percutaneous transhepatic biliary drainage et al.) and emergency cases as the responsible interventional radiologist is pressed for time, the implemented SSC was seen as a burden for a fluently workflow.

Furthermore, the short time span of the SSC implementation pilot phase and the first internal audit may be responsible for the relatively low adherence. 


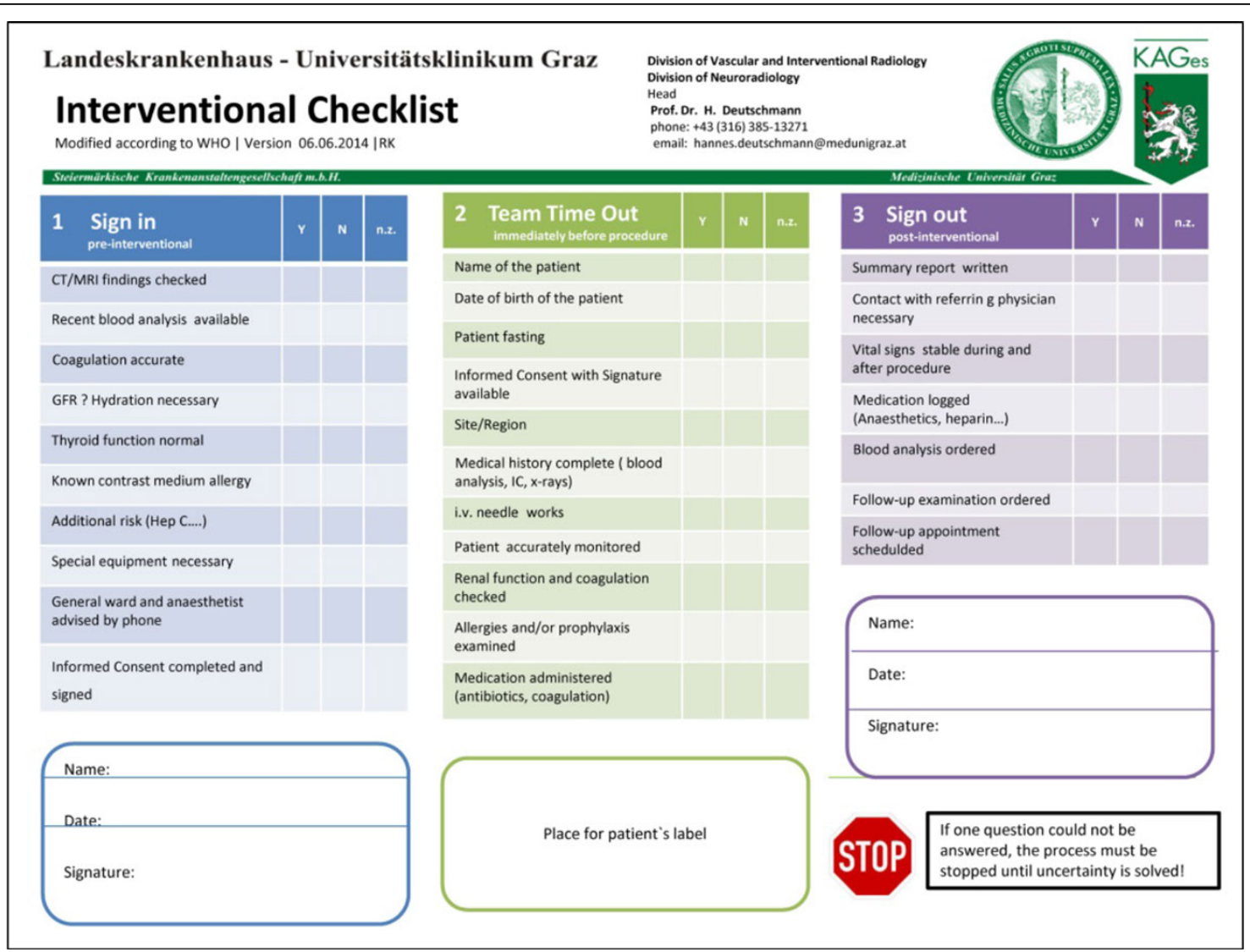

Figure $1 \mathrm{Implemented} \mathrm{Surgical} \mathrm{Safety} \mathrm{Checklist} \mathrm{at} \mathrm{the} \mathrm{division} \mathrm{of} \mathrm{vascular} \mathrm{and} \mathrm{interventional} \mathrm{radiology,} \mathrm{Graz.}$

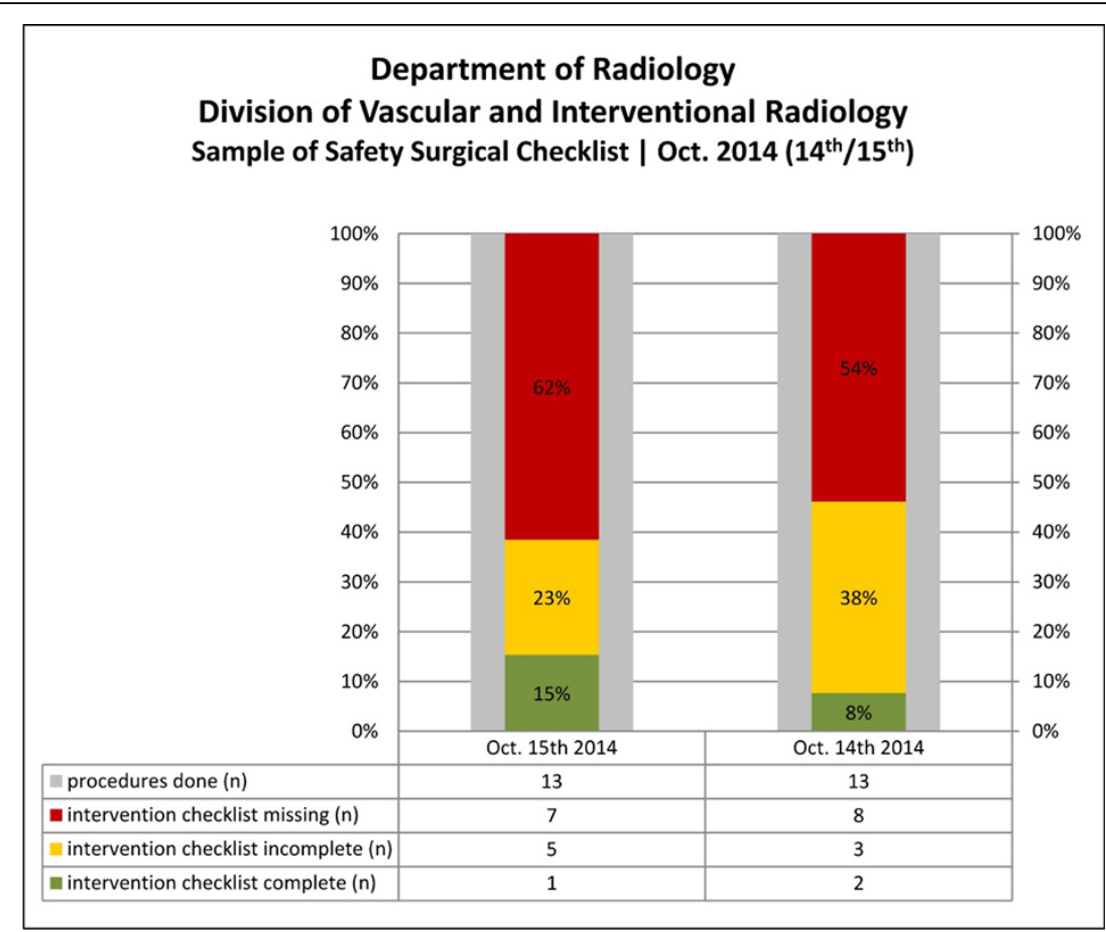

Figure 2 Results of an internal audit in regard to the compliance/adherence of the implemented SCC. 
Consecutively, repetitive outsourced training and assessment of the involved healthcare professionals might be a reasonable tool to improve the use of the surgical safety checklist.

\section{Competing interests}

The authors declare that they have no competing interests.

\section{Authors' details}

'Division of Vascular and Interventional Radiology, Department of Radiology, Medical University of Graz, Graz, Austria. ${ }^{2}$ Executive Department for Quality and Risk Management, University Hospital Graz, Graz, Austria. ${ }^{3}$ Division of Plastic, Aesthetic and Reconstructive Surgery, Department of Surgery,

Medical University of Graz, Graz, Austria.

Published: 30 October 2015

\section{References}

1. Battles JB, Lilford RJ: Organizing patient safety research to identify risks and hazards. Qual Saf Health Care 2003, 12(Suppl 2):ii2-ii7.

2. Ginsburg LR, Tregunno D, Norton PG, Mitchell Jl, Howley H: 'Not another safety culture survey: using the Canadian patient safety climate survey (Can-PSCS) to measure provider perceptions of PSC across health settings. BMJ Qual Saf 2014, 23(2):162-170.

3. Treadwell JR, Lucas S, Tsou AY: Surgical checklists: a systematic review of impacts and implementation. BMJ Qual Saf 2014, 23(4):299-318.

doi:10.1186/2056-5917-1-S1-A25

Cite this article as: Schnedl et al: Results from the Implementation of a Surgical Safety Checklist (SSC) at an Interventional Radiology Unit. Safety in Health 2015 1(Suppl 1):A25.

\section{Submit your next manuscript to BioMed Central} and take full advantage of:

- Convenient online submission

- Thorough peer review

- No space constraints or color figure charges

- Immediate publication on acceptance

- Inclusion in PubMed, CAS, Scopus and Google Scholar

- Research which is freely available for redistribution

Submit your manuscript at www.biomedcentral.com/submit 